\title{
Improving Students' Commitment Through a Simulation Method Based on Experience Learning Model
}

\author{
M.Th. Sri Rejeki Retnaningdyastuti \\ Universitas PGRI Semarang, Semarang, Indonesia
}

\author{
G. Rohastono Ajie \\ Universitas PGRI Semarang, Semarang, Indonesia
}

\begin{abstract}
The Undergraduate Program students of Guidance and Counseling who will become the candidates teachers or counselors at schools are expected to have commitment, later they will be able to give classroom guidance which will make the students satisfied. However, the fact shows, some students had the engagement with the less good standard. The lecturers do not use the effective learning method too. Therefore, an action research was done to improve students' commitment through simulation method based on experience learning model. The subject of the research was 30 students of Guidance and Counseling Program. The data were collected use documentation, interview, observation, and self-evaluation. The data were analyzed by used descriptive qualitative technique. The minimum total of the students who had good commitment was $80 \%$. The result shows in cycle I the students who had good commitment was 67\%; and in Cycle II, the total was more than the criteria, it was $90 \%$. The result of the research shows that students' commitment can be improved through simulation method based on experience learning model.
\end{abstract}

Keywords-commitment; simulation method; experience learning model

\section{INTRODUCTION}

Guidance and Counseling teachers/counselors at schools have a crucial role in serving the students to meet their needs for optimum development. The teacher/counselor of Guidance and Counseling should have the commitment to serve classroom guidance which will satisfy the students as the main customers at schools. The student satisfaction as the main customer is commonly used as an indicator of the quality of classroom guidance [1]. The students of Guidance and Counseling Program as the candidates of teachers/counselors require practices to develop commitment.

Commitment is a supreme moral value which reflects one's attitude to the perseverance and achieving the best in life [2]. Commitment also is related to responsibility. Therefore, the characteristics of commitment are perseverance and accountability. Perseverance can be by the interest of the task, care on the task, persistence, discipline, meticulous, and seek to be better. Responsibility is indicated by integrity, completeness of the task, and accept the consequences.

The result of our observation shows that students who took the subject of the Implementation of Classroom Guidance as teacher candidates of Guidance and Counseling indicate that their commitment has not achieved a good standard. To solve the problem, there should be an improvement in the learning method on the implementation of classroom guidance. The chosen method was the more efficient learning that was simulation method that based on experience learning model.

Classroom guidance is the help of guidance, and counseling teachers/counselors to the students through classroom approach to fulfilling the optimal development need to every student in class. Classroom guidance has the function of prevention, giving understanding, and development. In the program of comprehensive guidance [3] classroom guidance is called guidance curriculum program. Guidance curriculum is not a subject curriculum because the material of the curriculum is related to personal, social, education, and career guidance. In the subject of the Implementation of Classroom Guidance the students practice as teachers who give classroom guidance. Various basic skills of implementation are practiced which include opening the classroom guidance, asking the question, explaining, giving reinforcement, giving variation, and closing the classroom guidance [4].

In the education of teacher candidates, simulation method is a method of learning that will bring a real situation in a class by doing interaction between educators and students [5]. Experience learning model is a teaching model that emphasizes the reflection of students' experiences.

The use of simulation based on experience model is a method of learning that emphasizes reflection of students' expertise in a real situation in the classroom. The aim of simulation based on experience learning model is students have the experience as guidance and counseling teacher candidates in implementing classroom guidance service. The steps of simulation based on experience learning model are observing, planning, implementing and observing, reflecting, and communicating the experience.

Based on the above explanation, the research problem of this study is whether the student commitment can be improved through simulation method based on experience learning model. The research objectives were (1) to improve students' commitment to simulation method based on experience learning model, (2) to improve the lecturers' ability in teaching through simulation method based on learning experience model. 


\section{RESEARCH METHOD}

The action research of two cycles. Each cycle covered planning, actions, observation, and reflection [6]. The subject was 30 students of Guidance and Counseling program of Faculty of Education Science, the University of PGRI Semarang who took the topic of Implementation of Classroom Guidance. The researchers had the role as a planner, manager, reflector and evaluator. The colleague became the collaborator. The instrument of data collection was documentation, interview, observation, and self-evaluation. Analysis of the data used the descriptive qualitative technique. The minimum criteria of the total of the students who had good category were $80 \%$.

\section{RESULT AND DISCUSSION}

Based on the data analysis of students with Good commitment indicators in initial step until cycle II, the research result is shown in the table 1.

In cycles I and II, it can be seen that as the whole the percentage of commitment is increased in all indicators to the students with the good category. The percentage of the indicators of perseverance of the students with good category before the action, the cycle I, and cycle II is $39 \%, 52 \%$, and $62 \%$. The percentage of responsibility of the students with good category before the action, the cycle I, and cycle II is $11 \%, 15 \%$, and $28 \%$.

TABLE I. SUMMARY OF STUDENTS WITH GOOD COMMITMENT INDICATORS IN TWO CYCLES

\begin{tabular}{|l|c|c|c|c|c|c|}
\hline \multicolumn{1}{|c|}{ Category } & \multicolumn{2}{c}{ Initial Step } & \multicolumn{2}{c|}{ Cycle I } & \multicolumn{2}{c|}{ Cycle II } \\
\hline \multicolumn{1}{|c}{ Commitment } & $\boldsymbol{f}^{\mathrm{a}}$ & $\boldsymbol{\%}$ & $\boldsymbol{f}^{\mathrm{a}}$ & $\boldsymbol{\%}$ & $\boldsymbol{f}^{\mathrm{a}}$ & $\%$ \\
\hline Perseverance & 52 & 19 & 69.5 & 26 & 83.5 & 31 \\
Interest & 12 & 4 & 14.5 & 5 & 15 & 6 \\
Care & 11.5 & 4 & 14 & 5 & 15 & 6 \\
Persistence & 4.5 & 2 & 8.5 & 3 & 13.5 & 5 \\
Discipline & 12 & 4 & 14 & 5 & 14.5 & 5 \\
Meticulous & 5.5 & 2 & 9 & 3 & 13 & 5 \\
Seek to be better & 6.5 & 2 & 9.5 & 4 & 12.5 & 5 \\
Responsibility & 15.5 & 6 & 20.5 & 8 & 38 & 14 \\
Integrity & 4.5 & 2 & 6.5 & 2 & 12.5 & 5 \\
Completeness of the & 6 & 2 & 8 & 3 & 13 & 5 \\
task & & & & & & \\
Accept the & 5 & 2 & 6 & 2 & 12.5 & 5 \\
consequences & & & & & & \\
\hline Total & 135 & 50 & 180 & 67 & 243 & 90 \\
\hline
\end{tabular}

The results showed that the value of perseverance became the biggest determinant of student commitment. The increasing of perseverance value in cycle I is 17.5 or $6 \%$. Next on cycle II, there is an increase of 14 or $5 \%$. The total calculation result shows that the simulation method gives an increase of perservance value of 31.5 or $12 \%$. The next indicator that influences student commitment is responsibility. This value increased by 5 or $2 \%$ in cycle I and in cycle II increased by 7.5 or $6 \%$.

The whole result of the action improving the students' commitment to simulation method based on learning experience model can be seen in table 2 .
TABLE II. SUMMARY OF STUDENT'S COMMITMENT IN TWO CYCLES

\begin{tabular}{|l|r|r|r|r|r|c|}
\hline \multicolumn{1}{|c|}{ Category } & \multicolumn{2}{|c|}{ Initial Step } & \multicolumn{2}{c|}{ Cycle I } & \multicolumn{2}{c|}{ Cycles II } \\
\hline \multicolumn{1}{|c|}{ Commitment } & $\boldsymbol{f}^{\mathrm{a}}$ & $\boldsymbol{\%}$ & $\boldsymbol{f}^{\mathrm{a}}$ & $\boldsymbol{\%}$ & $\boldsymbol{f}^{\mathrm{a}}$ & $\boldsymbol{\%}$ \\
\hline Good & 15 & 50 & 20 & 67 & 27 & 90 \\
Fair & 12 & 40 & 9 & 30 & 3 & 10 \\
Bad & 3 & 10 & 1 & 3 & 0 & 0 \\
\hline Total & 30 & 100 & 30 & 100 & 30 & 100 \\
\hline
\end{tabular}

Table 2 shows that in initial step, the number of students with commitment value in category good only 15 people or $50 \%$. This percentage increased in the second cycle to $67 \%$ and in the second cycle increased to $90 \%$. Overall, the improvement actions the students' commitment to simulation method based on experience learning model. At the cycles, I have not been fulfilled the minimum criteria $80 \%$. Then it should have been continued in cycle II. In cycle II, the total was more than criteria. There is $40 \%$ improvement of the students' commitment to the proper category in cycle II. The research objectives have been achieved.

Based on the present study can be concluded that students' commitment can be improved through simulation method based on learning experience model in the subject of Implementation of Classroom Guidance. The Implementation of Classroom Guidance subject is the integration between theories and practices. One of the principals of choosing the teaching method is the conformity with the subject, so the most suitable are using simulation method. It is supported by Wrenn \& Wrenn (2009), which proposed that simulation method is a useful method to integrate theories and practices. By using the simulation method based on learning experience in cycle II, the students are able to show the commitment level is higher than the minimum criteria. The use of simulation method based on learning experience model is supported by Schuck (2010), which claimed that simulation method based on learning experience model could improve the ability to think, skillfulness, and the attitude of the students. According to Schuck (2010) the learning theories based on learning experience suggested by David Kolb becomes the base of teaching development by using simulation method.

The main idea of using learning experience model makes the students involved in the challenging experience and applies it to the new situation. By repeating the cycles through learning experience model, the students will get a better learning experience, so that their ability to think, become skillful, and their attitude in Bloom taxonomic moves to higher direction. The challenge given to the students is in accordance with Zona of Proximal Development (ZPD) of Vygotsky [7], [8], the challenge is adapted to students' experience, not too easy and not too difficult, and it can be achieved by the students.

\section{CONCLUSION}

The action research can be improved the students' commitment to simulation method based on learning experience model in the subject of Implementation of Classroom Guidance. Besides that, the lecturer can be enhanced her/his teaching quality through simulation method based on learning experience model in the subject of Implementation of Classroom Guidance. Thereby achieving 
one of the university's development strategy of combining learning with research. Suggested for similar action also done to other subjects.

\section{References}

[1] J. Xiao and S. Wilkins, "The effects of lecturer commitment on student perceptions of teaching quality and student satisfaction in Chinese higher education," J. High. Educ. Policy Manag., vol. 37, no. 1, pp. 98110, 2015.

[2] K. A. Khalidah, S. Rohani, and S. Mashitah, "Ethical Values and Commitment Towards Achieving Excellence: A Study on Public Boarding School Students In Malaysia.," Pertanika J. Soc. Sci. Humanit., vol. 22, 2014.

[3] G. Johnson, "Counseling Latino Students Using a Comprehensive Developmental Guidance and Counseling Model."

[4] A. Saban and A. N. Coklar, "Pre-Service Teachers' Opinions about the Micro-Teaching Method in Teaching Practice Classes," TOJET Turkish Online J. Educ. Technol., vol. 12, no. 2, 2013.

[5] J. Wrenn and B. Wrenn, "Enhancing learning by integrating theory and practice.," Int. J. Teach. Learn. High. Educ., vol. 21, no. 2, pp. 258-265, 2009.

[6] G. S. C. Hine, "The importance of action research in teacher education programs," Issues Educ. Res., vol. 23, no. 2, pp. 151-163, 2013.

[7] P. Schuck, "Simulation in education," Int. J. Educ. Res., vol. 31, pp. 561-576, 2010.

[8] C. Murphy, K. Scantlebury, and C. Milne, "Using Vygotsky's zone of proximal development to propose and test an explanatory model for conceptualising coteaching in pre-service science teacher education," Asia-Pacific J. Teach. Educ., vol. 43, no. 4, pp. 281-295, 2015. 